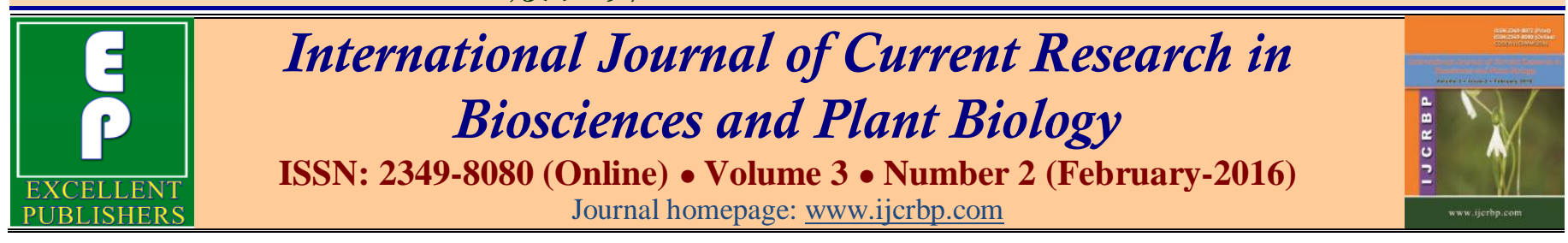

Review Article

doi: $\underline{\text { http://dx.doi.org/10.20546/ijcrbp.2016.302.009 }}$

\title{
Trash Free Living-Sustainable Future
}

\author{
Aparna Nayak* \\ Department of Biological and Agricultural Engineering, University of Idaho, Boise, USA \\ *Corresponding author.
}

\begin{abstract}
Zero Waste is a goal that is ethical, economical, and efficient and visionary, to guide people in changing their lifestyles and practices to emulate sustainable natural cycles, where all discarded materials are designed to become resources for others to use. Zero Waste means designing and managing products and processes to systematically avoid and eliminate the volume and toxicity of waste and materials, conserve and recover all resources, and not burn or bury them. "Zero waste is just what it sounds like producing, consuming, and recycling products without throwing anything away. Getting to a waste less world will require nothing less than a total makeover of the global economy, which thinkers such as entrepreneur Paul Hawken, consultant Amory Lovins, and architect William McDonough have called the Next Industrial Revolution”.
\end{abstract}

\section{Article Info}

Accepted: 26 January 2016

Available Online: 06 February 2016

\section{Keywords}

Environment

Waste generation

Waste management

Zero waste

\section{Introduction}

Zero waste can be understand by visualizing an industrial system in which nothing ever really expires or gets waste. The highly "unnatural" processes of chemical engineering, manufacturing, packaging, distribution, and disposal would all seek to a state of nature, where anything and everything is a renewable resource. The three R's of "reduce, reuse, recycle" would apply not just to products at the end of their life span, but to the materials and methods that created them. In this perfect system, each unit of energy consumed would be somehow counterbalance. Every industrial byproduct would reunite into something useful and gentle. Every beam of sunlight, scrap of garbage, and flush of the toilet would be pressed into service. No exceptions. Humankind would make obsolete the very concept of "waste" (Winter, 2007).

This is the environmental philosophy of "zero waste," a total vision of sustainability for our eco-panicked age. "Zero waste looks at what nature has given us as a model," says Larry Chalfan, executive director of the nonprofit
Zero Waste Alliance in Portland, Ore. "Everything at the end of its life, whether it's a flower or a dead body, is recycled; there are no toxic substances or 'waste' built up anywhere to cause harm to future generations. Everything is a resource to be used again". However, growing number of communities and businesses worldwide are adopting zero waste, adapting and attracted towards both environmental and economic advantages of it. Many big firms like Wal-Mart, Nike, Toyota, and Ford have all adapted zero waste for their operations. Similarly many of the cities of Oakland, San Francisco, and Seattle are also following the same. Many countries such as United States, New Zealand, Australia and Canada have dedicated themselves to the zero-waste challenge. Great Britain is publicizing the 2012 Olympics in London as the first "zero-waste games."

Zero Waste does not follow end of pipe waste management rather it refers to waste management and planning approaches which emphasize waste prevention. It is systems approach that aims for a massive change in the way materials flow through society, resulting in no waste. Zero waste includes more 
than eradicating waste through recycling and reuse, it emphases on rearranging production and distribution systems to reduce waste. Zero waste is more of a goal or ideal rather than a hard target. Zero Waste delivers supervisory principles for frequently working in the direction of eliminating wastes (Zero waste. Wikipedia).

The involvement of industries and government is prerequisite in eliminating waste from the beginning because they are presented with more advantages than individuals. Without their role zero waste will not be possible. Industry has control over product and packaging design, manufacturing processes, and material selection. Governments have the ability to form policy and provide subsidies for better product manufacturing, design and the ability to develop and adopt inclusive waste management strategies which can eliminate waste rather than just manage it. Zero waste can represent an economical alternative to waste systems, where new resources are continually required to replenish wasted raw materials. It can also represent an environmental alternative to waste since waste represents a significant amount of pollution in the world.

\section{Cradle-to-cradle / Cradle-to-grave}

Cradle-to-grave can be described as a linear model for materials that instigates with resource extraction, moves to product manufacturing, and, ends with a 'grave', where the product is disposed of in a landfill. Whereas, Cradle-to-cradle is defined as life-cycle analysis to describe a material or product that is recycled into a new product at the end of its life, so that eventually there is no waste (Cradle-to-cradle design. Wikipedia).

\section{Cradle-to-cradle functioning}

Cradle-to-cradle focuses on designing industrial systems so that materials flow in closed loop cycles that means the waste is minimized, and waste products can be recycled and reused. The cradle-to-cradle model is sustainable and considerate of life and future generations. The cradle-tocradle framework has evolved steadily from theory to practice. In the industrial sector, it is creating a new notion of materials and material flows. Just as in the natural world, in which one organism's 'waste', cycles through an ecosystem to provide nourishment for other living things, cradle-to-cradle materials circulate in closed-loop cycles, providing nutrients for nature or industry. DesignTex Fabric is an example of a closed loop, cradle-to-cradle product. It has designed an upholstery fabric, Climatex Lifecycle, which is a blend of pesticide and residue-free wool and organically grown ramie, dyed and processed entirely with nontoxic chemicals. All of its product and process inputs were defined and selected for their human and ecological safety within the biological metabolism. This allows the fabric trimmings to be made into felt and used by garden clubs as mulch for growing fruits and vegetables, returning the textile's biological nutrients to the soil.

The two categories in the cradle to cradle model, used in industrial or commercial processes are "technical" or "biological" nutrients. Technical nutrients are strictly limited to non-toxic, non-harmful synthetic materials that have no negative effects on the natural environment; they can be used in continuous cycles as the same product without losing their integrity or quality. In this manner these materials can be used over and over again instead of being "down cycled" into lesser products, ultimately becoming waste. Biological Nutrients are organic materials that, once used, can be disposed of in any natural environment and decompose into the soil, providing food for small life forms without affecting the natural environment. This is dependent on the ecology of the region; for example, organic material from one country or landmass may be harmful to the ecology of another country or landmass.

\section{Structure}

The Cradle to Cradle Products Innovation Institute's five certification criteria are ( $C 2 C$ certification $)$ :

1. Material health, which involves identifying the chemical composition of the materials that make up the product. Particularly hazardous materials (e.g. heavy metals, pigments, halogen compounds etc.) have to be reported whatever the concentration, and other materials reported where they exceed 100 ppm. For wood, the forest source is required. The risk for each material is assessed against criteria and eventually ranked on a scale with green being materials of low risk, yellow being those with moderate risk but are acceptable to continue to use, and red for materials that have high risk and need to be phased out. Grey for materials with incomplete data. The method uses the term 'risk' in the sense of hazard (as opposed to consequence and likelihood).

2. Material reutilization, which is about recovery and recycling at the end of product life.

3. Assessment of energy required for production, which for the highest level of certification needs to be based on at least $50 \%$ renewable energy for all parts and subassemblies. 
4. Water, particularly usage and discharge quality.

5. Social responsibility, which assesses fair labor practices.

The certification is available at several levels: basic, silver, gold, and platinum, with more stringent requirements at each. Prior to 2012, MBDC controlled the certification protocol.

\section{History of zero waste}

Zero waste get the name publically from the name of the company Zero Waste Systems Inc. (ZWS), founded by $\mathrm{PhD}$ chemist Paul Palmer in the mid-1970s in Oakland, California. The mission of ZWS was to find new homes for most of the chemicals being excessed by the nascent electronics industry. They soon expanded their services in many other directions. For example, they accepted free of charge, large quantities of new and usable laboratory chemicals which they resold to experimenters, scientists, companies and tinkerers of every description during the 1970s.

ZWS arguably had the largest inventory of laboratory chemicals in all of California, which were sold for half price. They also collected all of the solvent produced by the electronics industry called developer/rinse (a mixture of xylene and butyl acetate). This was put into small cans and sold as a lacquer thinner. ZWS collected all the "reflow oil" created by the printed circuit industry, which was filtered and resold into the "downhole" (oil well) industry. ZWS pioneered many other projects.

The successor to the ZWS function is the Zero Waste Institute (ZWI), also founded by Paul Palmer. Building on the lessons learned from ZWS, the ZWI considers recycling to be no more than an appendage to garbage creation and the garbage industry. ZWI likewise rejects all attempts to reuse garbage or any kind of waste product. Instead, ZWI calls for the redesign of all of the products of industry and commerce, and the processes that produce, sell and make use of them, so that discard never takes place and there is no waste generated needing to be reused or recycled. Discard is seen as the critical step, a commercial and psychological transfer of responsibility which breaks the chain of custody of a product, removes its owner and subjects it to the degradation of garbage management.

The ZWI rejects all association with the world of recycling, pointing out that there is no theory of recycling in existence; only a trusting hope that it can be useful. In many developed countries where the highest levels of waste generation they all initiated zero waste initiatives around 2010. Though, the waste generation is high in developing countries due to increased growth and development, in turn favors the zero waste in these places. In 1996 Canberra, Australia, was the first city in the world to officially declare a zero waste goal. Subsequently, many communities all around the globe have followed their own zero waste initiatives. This includes numerous towns and cities across the United States, Europe, and elsewhere in the developed world. New Zealand was the first country to have the majority of its local councils adopts zero waste goals. In 2010 Scotland has announced its own national zero waste plan.

Meanwhile, Canberra's deadline for zero waste in 2010 arrived, and the results are that although recycling rates have climbed as high as 75 percent, overall increases in the incoming waste stream have resulted in a net increase of waste to landfill. In North America, zero waste cities, such as New York, Toronto, and Vancouver, continue to export waste over hundreds of miles to distant landfill sites, as the last local landfills in those places have filled to capacity. The ideals of zero waste have been embraced by millions of people around the world; however, it remains to be seen how successful the movement can be in practice.

\section{2-2003}

The peak of this movement reached in 1998-2002, and since then has been moving from "theory into action" by focusing on how a "zero waste community" is structured and behaves. The website of the Zero Waste International Alliance has a listing of communities across the globe that have created public policy to promote zero-waste practices. The Eco-Cycle website represents how large nonprofit is leading Boulder County, Colorado on a Zero-Waste path. Also, in USA zero-waste organization named the Grass Roots Recycling Network that puts on workshops and conferences about zero-waste activities.

The City and County of San Francisco's Department of the Environment established a goal of zero waste in 2002, which led to the City's Mandatory Recycling and Composting Ordinance in 2009, with its ambitious goal of zero waste and policies, San Francisco reached a record-breaking $80 \%$ diversion rate in 2010, the highest diversion rate in any North American city. San Francisco received a perfect score in the waste category in the Siemens US and Canada Green City Index, which named San Francisco the greenest city in North America. The 
tension between zero waste, viewed as post-discard total recycling of materials only, and zero waste as the reuse of all high level function remains a serious one today. It is probably the defining difference between established recyclers and emerging zero-wasters. A signature example is the difference between smashing a glass bottle (recovering cheap glass) and refilling the bottle (recovering the entire function of the container).

The tension between the literal application of natural processes and the creation of industry-specific more efficient reuse modalities is another tension. Many observers look to nature as an ultimate model for production and innovative materials. Others point out that industrial products are inherently non-natural (such as chemicals and plastics that are mono-molecular) and benefit greatly from industrial methods of reuse, while natural methods requiring degradation and reconstitution are wasteful in that context.

Biodegradable plastic is the most prominent example. One side argues that biodegradation of plastic is wasteful because plastic is expensive and environmentally damaging to make. Whether made of starch or petroleum, the manufacturing process expends all the same materials and energy costs. Factories are built, raw materials are procured, investments are made, machinery is built and used, humans labor and make use of all normal human inputs for education, housing, food etc. Even if the plastic is biodegraded after a single use, all of those costs are lost so it is much more important to design plastic parts for multiple reuse or perpetual lives. The other side argues that keeping plastic out of a dump or the sea is the sole benefit of interest. Companies moving towards "zero landfill" plants include Subaru, Xerox and Anheuser-Busch. The Zero Waste Youth is an example of movement among the youth around the world, which was originated in Brazil and then spread to Argentina, Puerto Rico, Mexico, the United States, and Russia. The organization multiplies with local volunteer ambassadors who lead zero waste gatherings and events to spread the zero waste messages (Zero waste youth).

\section{Zero-waste living}

"With no solution in sight to America's overflowing landfills, there is no better time than now to try zerowaste living",

Trash is closely connected to every environmental problem we face today, from climate change and habitat destruction to water pollution and chemical exposure. It's also intensely personal and impacts every decision in our daily lives, including everything from how much money we spend to how much weight we gain. Only US generate more than 10 billion tons of solid waste each year, most of it from agricultural activities. This waste is consisting of waste produced by farm animals, slaughterhouses, and crop harvesting. Over 2 billion tons of waste a year only generates from mining industry. Residential and commercial wastes include everything from plastic bottles, aluminum cans, and rubber tires to yard trimmings, food wastes, and discarded appliances. As from the discussion board and the story of stuff we can conclude that on an average 4 pound per person per day solid waste generated at each home.

The storage, collection, transportation, processing, recovery, and disposal of solid waste results into very difficult task for solid waste management. Only collection and transportation includes $\$ 6$ billion a year in US. Most solid waste is transported to dumps and landfills; the rest is incinerated. In 1970, studies on solid waste indicates, as many as 90 percent of the dumps and 75 percent of the municipal incinerators were considered inadequate, and were major polluters of air, land, and water (Zimring and Rathje, 2012). The garbage that is managed by local governments is known as municipal solid waste (MSW). Specifically, MSW is waste generated by commercial and household sources that is collected and either recycled, incinerated, or disposed of in MSW landfills. The EPA separates MSW into several categories, including containers and packaging, yard wastes, durable goods, and nondurable goods.

During the 1980s, solid waste management issues emerged in the United States due to the increasing amounts of solid waste generated, shrinking landfill capacity, rising disposal costs, and strong opposition to the sitting of new solid waste facilities. This problem was illustrated by the much-publicized Mobro garbage barge, which traveled on a six-month odyssey before the garbage was finally disposed of in New York State, where it was originally generated. The data gathered around the years shows generation of MSW has grown steadily, from 88 million tons per year, or 2.7 pounds per person per day, to 229.9 million tons, or 4.62 pounds per person per day in recent studies. The largest component of the MSW stream is paper and paperboard products (38.1\%), with yard trimmings the second most predominant component (12.1\%). Combustion of MSW and recovery through recycling are now a common practice in the United States (Humes, 2013). 


\section{Facing own trash addiction}

To change the country's trash addiction, we first have to address own trash problem first. I had heard about people in other parts of the world living "trash free," which basically means sending nothing to the landfillever. I wondered if the same could be done here in the United States, in a country where people produce more trash than anywhere else in the world.

\section{So what exactly does "Trash Free" mean?}

Trash-free living means different things to different people, for some families, a trash-less life might mean moving from filling a giant, 64-gallon garbage can a week to filling a 32-gallon garbage can once a month. To others, it might mean a small grocery sack of garbage a week. To still others, going trash free means sending absolutely nothing to the landfill at all. The last category is belongs to zero waste, where we create no garbage at all.

\section{Benefits of a trash-free life}

In addition to reducing your impact on the planet, here are some other benefits of your new zero-waste lifestyle (Johnson, 2013 and 2015):

1) Simpler life: We all wish we had a little more time in the day. Trash-free living helps streamline many areas of your life, from grocery shopping to cleaning the house. You'll learn to repurpose everyday products like baking soda and lemon juice to do double duty, in the kitchen and in the cleaning bucket. You'll spend less time at the store and more time at home with family and friends.

2) Saves Money: Going trash-free means becoming much more careful about your purchases. You'll deliberately buy items that can serve dual purposes, and you'll look for durable goods that last a long time before breaking. Since waste is a sign of inefficiency, the reduction of waste usually reduces costs. For example, Hewlett Packard in Roseville, CA reduced its waste by 95\% and saved \$870,564 in 1998. Epson in Portland, OR has reduced its waste to zero and has saved $\$ 300,000$. Interface, Inc. in Atlanta, GA has eliminated over $\$ 90 \mathrm{M}$ in waste. Xerox Corp., Rochester, NY has had a Waste-Free Factory environmental performance goal since the early 1990s. The criteria include reductions in solid and hazardous waste, emissions, energy consumption, and increased recycling. Savings were \$45M in 1998.
3) Supports local businesses: Shopping locally benefits the environment, because goods are not trucked all over the country for consumption. Studies show that "three times as much money stays in the local economy when you buy goods and services from locally owned businesses instead of large chain stores," according to the Institute for Local Self-Reliance.

4) Eat healthier: Cutting out garbage means eating more whole foods that don't come over packaged in plastic. You'll shop the periphery of the grocery store and frequent local farmers' markets, buying good-foryou foods like fruits and veggies and locally sourced meat, dairy, and eggs.

5) Preserve planet for future generations: Landfills are overflowing, our water systems are becoming polluted, and animal species are becoming endangered and going extinct at an alarming rate, and we are finding toxic chemicals in our food and beauty products. Every time you choose sustainable over throwaway, you're doing your part to eliminate these problems. The less garbage we make collectively, the less litter there will be to spoil nature's beauty.

6) Reduces your exposure to toxic chemicals and artificial colors and sweeteners: A garbage-free life means you'll choose healthier options than the prepackaged, processed foods that line the grocery store shelves. We know food-like substances like Pop-Tarts and Cheetos aren't good for us - avoiding the garbage is just one more reason to look for healthier alternatives.

7) More self-sufficient: One of the most enjoyable parts of a garbage-free life is learning some skills our culture has all but forgotten. Pretty much anything store-bought can be made at home, if you have the time and interest.

8) Supports sustainability: A Zero Waste strategy supports all three of the generally accepted goals of sustainability - economic wellbeing, environmental protection, and social wellbeing:

Economic well-being is improved by enabling organizations to identify inefficiencies in processes, products and services and thereby to find cost-saving solutions to them.

- Waste Reduction=Improved efficiency and lowers costs

- Costs of compliance with regulations is reduced

Environmental protection is enhanced by reducing 
(ideally to zero) hazardous and solid wastes to nature and by reducing the need for energy generation and hydrocarbon extraction.

- Reduces demand for resources and energy from nature

- Reduces wastes to nature

Social wellbeing is enhanced through efficiency improvements that allow more resources to be available for all. In addition, more complete use of "wastes" will create jobs in return logistics and reprocessing activities.

- Waste managers become resource managers

- Opportunities in return logistics

- New products from recovered materials

9) Improved material flows: Today's system uses large amounts of new raw materials .In addition, large amounts of materials are sent to landfills or incinerated. A Zero Waste society would use far fewer new raw materials and send no waste materials to landfills. All materials would either return as reusable or recycled materials or would be suitable for use as compost.

\section{How to live without garbage (Jhonson, 2013)}

\section{Change habits}

Changing habit requires train own self. For e.g. in our daily routine what we do, If I forget a cloth grocery bag, I make myself buy another. If I forget a travel mug or water bottle, I do without or buy another. If I forget a container and I'm eating out, I have to eat all of the food or find a creative way to get my leftovers home. Through repeated training, I almost never forget these items anymore.

\section{Attentive shopping}

I have learned to avoid garbage by shopping well. Always try to prevent the garbage. Prefer to buy in bulk, buy local, buy second-hand, and always prefer item that does not come in plastic.

\section{Source Reduction}

Source reduction, also known as waste prevention, is a front-end approach to addressing MSW problems by changing the way products are made and used.

It represents an attempt to move away from the traditional "end-of-the-pipe" waste management approach used in the past. Source reduction at the "beginning of the pipe" is defined as the design, manufacture, and use of products in a way that reduces the quantity and toxicity of waste produced when products reach the end of their useful lives. Wasteprevention activities include product reuse (e.g., reusable shopping bags), product material volume reduction (e.g., eliminating unnecessary product packaging), reduced toxicity of products (e.g., use of substitutes for lead, mercury, and other toxic substances), increased product lifetime (e.g., design of products with a longer useful life), and decreased consumption (e.g., changing consumer buying practices, bulk purchasing). In 1996 the EPA reported that 23 million tons of MSW had been source-reduced, approximately 11 percent of the 209.7 million tons of MSW generated that year. Businesses, households, and state and local governments all play an active role in implementing successful source reduction programs.

\section{Recycling}

Recycling is defined as converting a waste into usable or marketable materials. It includes composting, diverts potentially large volumes of material from landfills and combustors, and prevents the unnecessary waste of natural resources and raw materials. It also results to a reduction in greenhouse gas emissions, energy conservation, and the preservation of biodiversity and habitats that would otherwise be exploited for virgin materials. Furthermore, this also creates new manufacturing jobs, boost the economy, and facilitate U.S. competitiveness in the global marketplace.

Also, recovered materials have constantly expanding markets for a reuse material. Recycled-content newspapers, stationery, corrugated containers, and toilet paper are some examples of how discarded paper is recycled.

Composting is another good example of reducing and reusing, denotes the decomposition of organic matter by microorganisms into a stable humus material that is used primarily on the land to improve soil quality. It has been used by many communities to conduct large-scale centralized composting of yard waste in an effort to save landfill capacity. Individuals can also reduce waste by composting yard waste in their backyards. The composting of yard waste has seen tremendous growth over the years. About half of all household garbage is compostable. If you want to take just one step toward reducing your garbage, then build a compost pile. It's 
easier than you think! Each American throws away more than 4 pounds of garbage a day. How long does it take to biodegrade?

Paper ... 2 to 5 months

Orange peel ...6 months

Plastic bag ... 10 to 20 years

Aluminum/tin can ... 50 to 100 years

Battery ... 100 years

Glass bottle ... 1 million years

Plastic soda bottle ... never biodegrades

Styrofoam (polystyrene) ... never biodegrades

\section{Broadly applicable}

The benefits of a Zero Waste strategy can be achieved in nearly any kind of organization. Some examples are:

- Community programs can be designed to consider all uses of materials and energy both in operations and services. Focus on zero solid waste to landfills and zero wasted energy can result in new jobs not only in the recovery process, but also in the use of recovered waste products as raw materials to produce new products.

- Business programs can be designed to uses of energy and materials in products, processes and services. Focus on increasing efficiency by eliminating solid and hazardous waste, process wastes, wastes in production operations (motion, time, over production, misprinted invoices, etc.) and striving for energy reduction.

- Industry-wide programs can be very effective if the industry members are willing to work together. As such, it reaches its maximum effectiveness in reducing energy and material use and achieving environmental improvements.

- School programs when applied to all school activities and classroom teaching can save money while providing important education to help the younger generation be prepared to contend with coming changes. Zero waste can be applied not only to energy and material use, but also in the facilities plant, offices, classrooms and cafeteria.

- Home programs can be developed that include energy savings, changes in purchasing habits, reduction in the toxicity of cleaning agents, use of more appropriate fertilizers and pesticides. This can help provide badly needed education for the general population.

\section{Conclusion}

Currently we have a growing population faced with limits of resources from the environment. We understand that our society and industrial systems must begin to mimic nature and move from being primarily linear to being cyclical. Each material must be used as efficiently as possible and must be chosen so that it may either return safely to a cycle within the environment or remain viable in the industrial cycle. This can also be understand by one of the exercise done by me i.e. carbon footprint calculator which will calculate your carbon footprint and the result was really an eye-opener for me. The results indicates that if consider only my requirement for a daily life span which can only be fulfill by 4.2 earth, the results specifies one planet is not sufficient for me. This will indicates how individual contributes for any changes which will occur to whole society, community and to across the world.

The vision of Zero Waste can be seen as a solution to these needs and a key to our grandchildren's future. Zero solid waste, zero hazardous waste, zero toxic emissions, zero material waste, zero energy waste and zero waste of human resources will protect the environment and lead to a much more productive, efficient, and sustainable future. The use of an endpoint goal of "zero" recognizes that simple making small steps without a goal may not achieve a sustainable future while use of a clear defined goal will lead to more rapid innovative improvements.

As an individual I would suggest everyone to follow the pollution prevention hierarchy and practice to stay as high as possible in the hierarchy. The best thing which can do and contribute towards reduction of solid waste is to reduce it first at its source which we can easily start from our home by following some zero waste technique. Zero Waste promotes not only reuse and recycling, but also, and more importantly, promotes prevention designs that consider the entire product life cycle. These new designs will strive for reduced materials use, use of recycled materials, and use of more benign materials, longer product lives, repair ability, and ease of disassembly at end of life.

A Zero Waste strategy is a sound business tool that, when integrated into business processes, provides an easy to understand stretch goal that can lead to innovative ways to identify, prevent and reduce wastes of all kinds. It strongly supports sustainability by protecting the environment, reducing costs and producing additional jobs in the management and 
handling of wastes back into the industrial cycle. A Zero Waste strategy may be applied to businesses, communities, industrial sectors, schools and homes. Everyone contributes to national and global pollution and this cannot solved by governments alone. For their policies to work effectively the actions of the individual are required. The collective action by individuals would reduce solid waste generation, water use, and energy use and results into whole reduction in Pollution around the globe.

\section{Conflict of interest statement}

Authors declare that they have no conflict of interest.

\section{References}

C2C Certification Criteria. http://www.c2ccertified.org/ resources/collection-page/cradle-to-cradle-certifiedresources. Web accessed Feb 12, 2015.

Cradle-to-cradle design. From Wikipedia, the Free Encyclopedia. http://en.wikipedia.org/wiki/Cradle-tocradle_design. Web accessed Feb 12, 2015.

Humes, E., 2013. Garbology: Our Dirty Love Affair with Trash. March 5, 2013.
Johnson, B., 2015. Zero waste home. http://zerowastehome. blogspot.com/p/about.html. Web accessed March 16, 2015.

Johnson, B., 2013. Zero waste home: The ultimate guide to simplifying your life by reducing your waste. April 9, 2013.

Winter, J., 2007. A world without waste. The 'zero waste' movement imagines a future where everything is a renewable resource. Sound impossible? From New Zealand to New England, it's already changing the way governments and companies do business. http://www.boston.com/news/education/higher/articles/20 07/03/11/a_world_without_waste/?page=full. $\quad$ Web accessed Feb 12, 2015.

Zero Waste International Alliance. ZW Definition. http://zwia.org/standards/zw-definition/ Web accessed Feb 10, 2015.

Zero Waste Youth. http://zerowasteyouth.org/site/. Web accessed Mar16, 2015.

Zero Waste. From Wikipedia, the free encyclopedia. http://en.wikipedia.org/wiki/Zero_waste. Web accessed Feb 12, 2015.

Zimring, C. A., Rathje, W.L., 2012. Encyclopedia of Consumption and Waste: The Social Science of Garbage. February 27, 2012.

\section{How to cite this article:}

Nayak, A., 2016. Trash free living-sustainable future. Int. J. Curr. Res. Biosci. Plant Biol. 3(2), 69-76. doi: http://dx.doi.org/10.20546/ijcrbp.2016.302.009 